\title{
Development of a Wall Collector Unit and Phase Change Material (PCM), Air Heat Exchanger for Heating Application in Greenhouses
}

\author{
Liang $\mathrm{Hao}^{1,2}$, Yang Qichang ${ }^{1,2} \&$ Luis Alejandro ${ }^{1}$ \\ ${ }^{1}$ Institute of Environmental and Sustainable in Agriculture, Chinese academy of agriculture science, Beijing, \\ China \\ ${ }^{2}$ Key lab. for energy saving and waste disposal of protected Agriculture, ministry of agriculture, Beijing, China \\ Correspondence: Luis Alejandro, Chinese Academy of Agricultural sciences Center for protected Agriculture and \\ environmental engineering, Room 209, No.12, South Street, Zhong Guan Cun, Beijing 100081, China. E-mail: \\ H.273@live.com
}

Received: November 7, 2012 Accepted: November 29, 2012 Online Published: December 26, 2012

doi:10.5539/eer.v3n1p24 URL: http://dx.doi.org/10.5539/eer.v3n1p24

\begin{abstract}
Greenhouse heating is essential in the northern region of China during winter season in order to maximize crop production in terms of quality and quantity and thus increase their overall efficiency. But the use of heating systems faces the problem of high running cost and noxious gases emission for heating systems based on fossil fuel and there is also a risk of frost cropping for electrical heating systems due to electrical power failure during heavy weather conditions. In this paper the performance of flat plate collector and a PCM serpentine heat exchange is investigated. An eutectic mixture $\mathrm{CH}_{3} \mathrm{COONa} \cdot 3 \mathrm{H}_{2} \mathrm{O}-\mathrm{HCONH}_{3}$ was used as a latent heat storage material, this material possess a melting temperature of $40.5^{\circ} \mathrm{C}$, relatively higher compared to commonly used phase change materials for heating applications. The energy capacity of the PCM during charge and discharge phase has been determined based upon the measurement results made in the heating process during February 2012, one of the coldest winter months in Beijing, China. It was observed that the average net energy efficiencies was $45 \%$, therefore the PCM in study, was founded to be suitable for solar thermal storage applications.
\end{abstract}

Keywords: flat plate collector, latent heat storage, heat exchanger, PCM, Greenhouse

\section{Introduction}

With a vast land area, China is subject to the most extreme and worst weather conditions, from bitter cold winters to unbearable heat during summer. The winter in the northern region starts from the latest weeks of November and remains until March or April, considering January and February as the coldest months, with temperatures dropping to $-40^{\circ} \mathrm{C}$. Due to this factor, the use of greenhouses has a special importance for the agricultural sector in the northern region of China. These facilities represent a solution to crop cultivation during the coldest months of winter, allowing crop availability on the local and national markets. Greenhouses are by nature thermal collecting structures, the inside surface collects solar radiation heat during the day and re-radiates it to the Greenhouse inside environment during the night. But usually such heat radiation is not capable to fulfill the crop heat demand adequately. Therefore, the use of heating systems is essential to control the greenhouse indoor temperature and to provide adequate climatic conditions for crop growing during winter season. Among the advantages provided by the heating systems, we can mention: rapid growing and earliness, better control of the inside humidity and danger of disease infestation; reduction on chemical usage with positive consequences on the environment and health in general (Bailey, 2001).

At the same time, the installation and use of heating systems faces the problem of high operational cost, since there is a constant increment in energy prices. As reported by (Bailey, 2006), all types of heating system must increase productivity and sufficient earliness to justify the investment and running costs. Due to this fact, alternative energy sources for greenhouses heating have gained utmost interest in recent years. Some of the most important sources of energy are solar collectors and thermal storage energy (TES); these systems make use of Phase Change Materials (PCM) to store heat energy. The use of solar power is an increasingly attractive alternative as it is a stand-alone energy source, does not require a connection to a power grid, and the sun provides an unlimited and virtually endless supply of energy. In order to convert the solar radiation energy into thermal energy, the use of solar collectors has been widely use, the collector unit is placed outside the facilities 
and serves to heat the facilities in interest. In a greenhouse, the use of solar thermal energy covers one part of the crop heating demand needed during the day, as solar radiation is available during day only; its usage during night time required an efficient storage medium, so the excess of heat is stored for later use during the night. The solar thermal energy can be stored as sensible heat or latent heat. To store the same amount of energy, the sensible heat storage required significantly large quantities of storage medium, compared to the latent heat storage. In most sensible storage systems, the energy is stored in water or rock, which occupied larges spaces. A clear example of the difference for heat storage between sensible and latent heat storage can be founded in concrete blocks, which heat capacitance is approximately $1.0 \mathrm{~kJ} / \mathrm{KgK}$, while for hydrated salts, its capacitance during store and release is $190 \mathrm{~kJ} / \mathrm{KgK}$. In latent heat storage, the use of a PCM is considered as storage medium. PCM's are chemical substances, which possess a high fusion heat, which melts and solidifies at a certain temperature, they are capable of storing and releasing large amounts of energy compared to sensible heat storage materials. The process of absorbing or releasing occurs when the material changes from solid to liquid and vice versa.

Basically, PCM's can be classified into four types depending on its application: solid-solid, solid-liquid, solid-gas and liquid-gas phase change. However, the most common phase change material used for space heating application is the solid-liquid. Among the most used solid-liquid change PCM are Salt Hydrates, Fatty Acids, Esters, and a large quantity of Paraffin, some of these are considered products of oil refining or polymerization and are available in large amounts.

Various research works about solar thermal collectors and its application and combination with different storage mediums have been carried out in the past decade. Husseyin and Aydin (2009), conducted a study on the performance analysis of a latent heat storage system. In their study, a 10 piece flat plate air solar collector was used to heat up a greenhouse located in Turkey. A corrugated plate, reverse corrugated plate, trapeze plate, reverse trapeze plate and a flat absorption plate in combination with a phase change material were used for this work. They reported that such system is capable to provide $18-23 \%$ of the total daily thermal energy of a greenhouse for about 3-4 hours in comparison to conventional heating devices. And the difference in temperatures between indoor and outdoor was around 6-9 ${ }^{\circ} \mathrm{C}$. In a more recent study, Laurent and Annabelle (2011) developed a small scale composite solar wall integrated with a phase change material. Their work focuses on the solar wall performance analysis, principally on the delay between absorption of solar radiation and released energy to the environment. Their study makes use of a mixture of calcium chloride potassium chloride and additives that possess a melting temperature of $27^{\circ} \mathrm{C}$. They reported, composite wall have the advantage of heat release delay. This wall installation is rather to be used in premises occupied during day.

In the same manner, Phase Change Materials had been extensively studied for space heating applications, due to their capacity to store large amounts of heat when they change from solid to liquid. Studies about the application and utilization of PCM dates back to 1980, when Kern and Aldrich (1979), use calcium chloride hexahydrated as a PCM to investigate the heat energy storage capacity for a $36 \mathrm{~m}^{2}$ greenhouse that use fiberglass as insulation material. They reported that the thermal performance for this PCM higher compared to sensible heat storage mediums. In a recent study Husseyin and Aydin (2008) developed a hybrid system that make use of a GHPS integrated $\mathrm{PCM}$ been $\mathrm{CaCl}_{2} \cdot \mathrm{H}_{2} \mathrm{O}$ the $\mathrm{PCM}$ used as thermal storage material because of its high latent fusion per unit mass, chemical stability, availability in large quantities and low price. To fulfill the heat energy demand during winters in Turkey, their results showed that this system was capable to increase the greenhouse indoor temperature by $5-10^{\circ} \mathrm{C}$ and the $\mathrm{PCM}$ increases by $1-3^{\circ} \mathrm{C}$ depending on the environment temperature, preventing in this way the risk of crop frost during winter nights. In other study, El-Bassuani et al. (2003) conduct a research where they combined urea sodium acetate trihydrated, urea sodium acetate trihydrated and lead acetate trihydrated as phase change material for energy storage purposes. They reported that such system composed by a mixture of urea sodium and acetate lead has the capacity to store $286 \mathrm{~kJ} / \mathrm{kg}$. As a remark from this study, the composition mentioned before can be modified by adding other organic or inorganic compounds, rising the melting temperature and making this PCM suitable for applications in hot climatic regions. This paper presents the analysis performance of a north wall collector unit with a PCM heat accumulator. The main purpose is to develop an air-type solar collector with high thermal performance that is suitable for heating applications, and can be set up inside a greenhouse in order to optimize the space utilization. The literature review shows us that small works on greenhouse heating in the northern region of China has been carried out, focusing on solar collectors in combination with PCM's. Therefore, this paper will provide simplicity to solar collector's developers and information on the heating performance of the PCM used on greenhouses. As well as this system represents a potential application, there is a special focus in remote areas where the electric supply is non-existent or non-constant. 


\section{Experimental Setup}

In this study, a north wall collector unit with a PCM heat accumulator was developed. This system represents an alternative solution to greenhouse heating demands for remote areas in the northern region of China, where an electrical supply is not available, and also can be used in combination with conventional heating systems in order to reduce the energy consumption. The schematic diagram of the system is given in Figure 1, and its main components are: PCM containers, Air ducts, Absorption plate, Serpentine PCM air heat exchanger, Air inlet valve, Air Outlet valve, and air separating valve. The hollowed stainless steel bars used to contain the PCM are shown in Figure 2. The facilities used for testing are shown in Figure 3a, b and c. The experimental set up consists of a collector unit equipped with a serpentine heat exchanger at the top side of the absorption plate; this unit was set up over the north wall inside a Chinese solar greenhouse with an angle of 90 degrees, respect to the horizontal. The collector unit collects the solar radiation and stores it to be used during the night by using a PCM heat exchanger. The absorption plate was set inside a PVC box at distance of $10 \mathrm{~mm}$ measured form the glazing plate. A galvanized steel sheet with a thickness of $0.5 \mathrm{~mm}$ and black chrome selective coating was used as an absorption plate. The PVC used to construct the solar collector box has a thickness of $2 \mathrm{~mm}$, a length of $102 \mathrm{~mm}$ and a width of $102 \mathrm{~mm}$. Its exterior is covered by polystyrene foam with a thickness of $20 \mathrm{~mm}$ and thermal conductivity of $0.042 \mathrm{~W} / \mathrm{mK}$. A single polycarbonate rigid film was used as a glazed material to maximize solar radiation on the absorption plate. Some of the polycarbonate properties are: good transmittance, high impact resistance, good temperature capability (270F), light weight, good life and low transmittance in the long IR, reducing heat loss. Two radial fans, $110 \mathrm{v}, 60 \mathrm{~Hz}, 1.3 \mathrm{~A}, 12 \times 12 \mathrm{~cm}$ in size and a CFM of 110 were set inside the serpentine heat exchanger chamber to facilitate air circulation, inside the heat exchanger chamber and towards the adsorption plate. The air circulates through PVC ducts with a $30 \mathrm{~mm}$ diameter covered by industrial Floormate foam insulation with a $20 \mathrm{~mm}$ thickness and a thermal conductivity of $0.028 \mathrm{~W} / \mathrm{mK}$. 3 ball valves were used at the end and mid-way of the air duct to prevent reversibility during the discharging process. The PCM was sealed inside the 12 stainless steel tubes with a $100 \mathrm{~mm}$ length, positioned horizontally inside the serpentine heat exchanger chamber, 12 thermocouples (T-Type cooper constant) were used to measure the thermal behavior of the PCM inside the tubes. A Binary eutectic composition $\left.\left(\mathrm{CH}_{3} \mathrm{COONa} \cdot 3 \mathrm{H}_{2} \mathrm{O}-\mathrm{HCONH}_{3}\right)\right)$ was used as phase change material in a ratio of 3:1. This eutectic PCM was developed by Takahiro Wada (1983), and possess a melting temperature of $40.5^{\circ} \mathrm{C}$, with a fusion heat of $255 \mathrm{KJ} / \mathrm{kg}$. $99 \%$ composition purity was used in this work. The PCM charging and discharging process period occurs as follows: when the absorption plate is heated up by the solar radiation, the electric fans are activated pulling the heated air from the upper duct into the PCM heat exchanger chamber, at this moment, the valve $\mathrm{C}$ is closed to procure a direct air flow into the PCM heat exchanger. Then, the hot air circulates through the serpentine PCM chamber and the 12 stainless steel bars that contain the eutectic composition, until it reaches the left side of the collector. At this moment, the valve B is closed and the air is redirected to the absorption plate to be circled again.

The release process is merely a circuit between the greenhouse internal air and the PCM heat exchanger and it occurs in a similar way like in the collecting process. After the total amount of PCM contained in the stainless steel tube change its phase (solid-liquid), the three valves are closed and reopened during the night time when the heat stored is need for greenhouse heating. Then, the valves $\mathrm{C}$ and B are opened; the electrical fan pulls air into the chamber and exits by the valve $\mathrm{C}$ to the greenhouse environment. Three more thermocouples (T-type) were set at the absorption plate inlet and outlet to measure their respective temperatures. A data acquisition system was used to record the different parameters during collection and release cycles with 20 min intervals, the properties recorded were: ambient air temperature, humidity, inlet and outlet temperature and solar intensity over the absorption plate surface. 

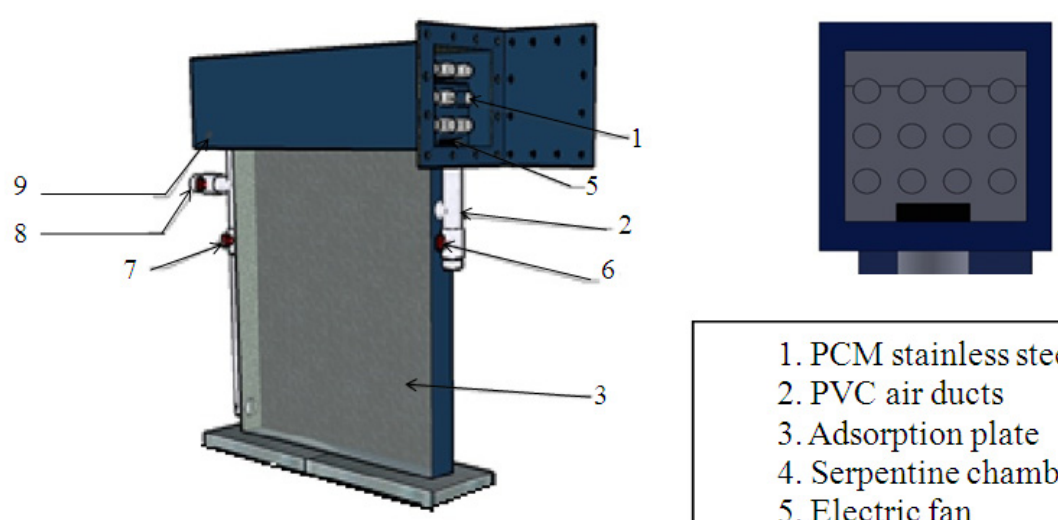

1. PCM stainless steel tubes

2. PVC air ducts

3. Adsorption plate

4. Serpentine chamber

5. Electric fan

6. Valve B

7. Valve A

8. Valve C

9. Heat exchanger chamber

Figure 1. Solar COLLECtor

a)

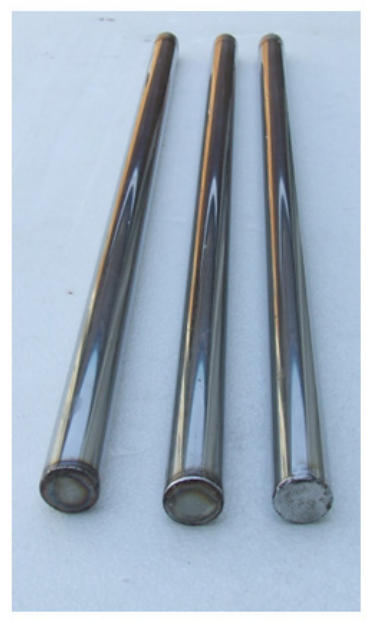

b)

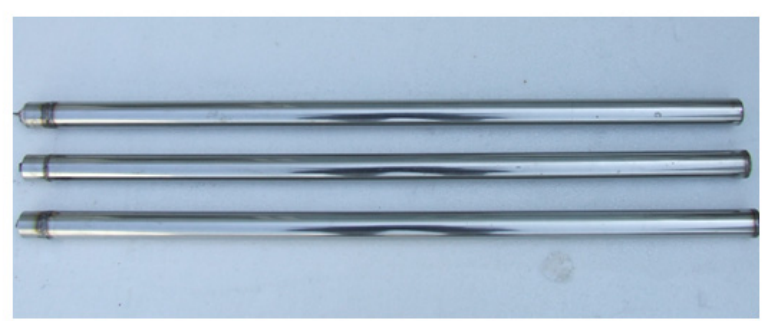

Figure 2. PCM containers (stainless steel)

\section{Measurements}

Experiments were conducted during the months of January and February of 2012 in the city of Beijing, China. The heating system was designed to be set over a north wall, located inside a Chinese solar green house in order to act in a similar way as a thermal wall. A Chinese solar greenhouse positioned towards south, with a base dimension of 8 meters, a north wall height of 2.8 meters and a width of 80 meters, was subdivided into polyethylene plastic film separated sections for system testing. Figure $3 \mathrm{a}$ and $3 \mathrm{c}$ shows the inside facilities and the north wall used in this experiment. Experiments were carried out to study the thermal behavior of a eutectic composition $\left(\mathrm{CH}_{3} \mathrm{COONa} \cdot 3 \mathrm{H}_{2} \mathrm{O}-\mathrm{HCONH}_{3}\right)$ and the possibility of heating application for Chinese solar green houses. The experiments were carried out at the same time period from 9:00am-15:00pm during test days. A data acquisition system (CR1000 data logger, Campbell, USA CMP3, kipp and zonen, USA) was used to record the different parameters during the heating and realizing cycles at an interval of $20 \mathrm{~min}$. The properties recorded were: ambient air temperature, humidity, inlet and outlet temperatures and solar intensity over the adsorption plate. Different air flow rates of $0.2 \mathrm{~kg} / \mathrm{min}, 0.6 \mathrm{~kg} / \mathrm{min}$ and $1.0 \mathrm{~kg} / \mathrm{min}$ were tested as well. The temperature variation at the heat exchanger inlet and outlet with different air circulation rate and solar radiation measurement for different times during the days are showed in Figure 4. There was a similar finding on solar radiation and solar irradiance during test days from 10:30am-13:30pm equal to $600 \mathrm{~W} / \mathrm{m}^{2}$. 


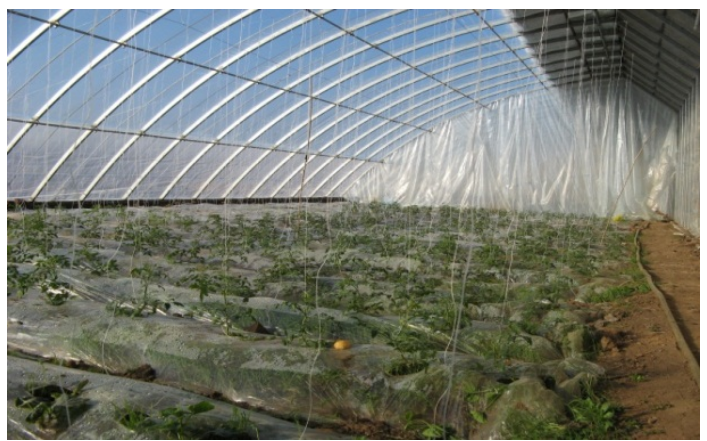

a)

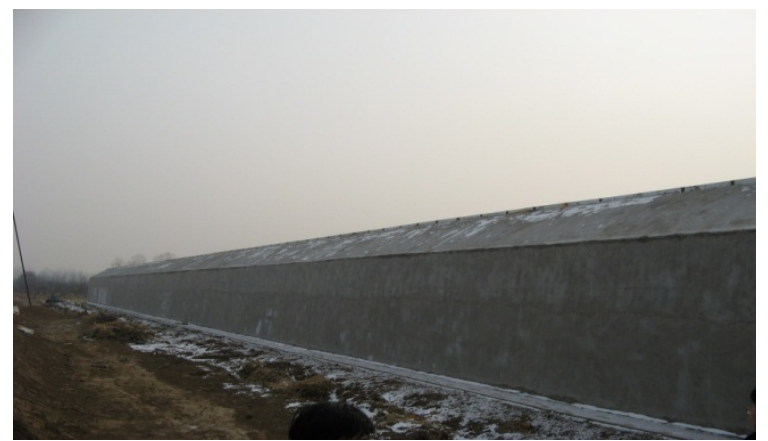

b)

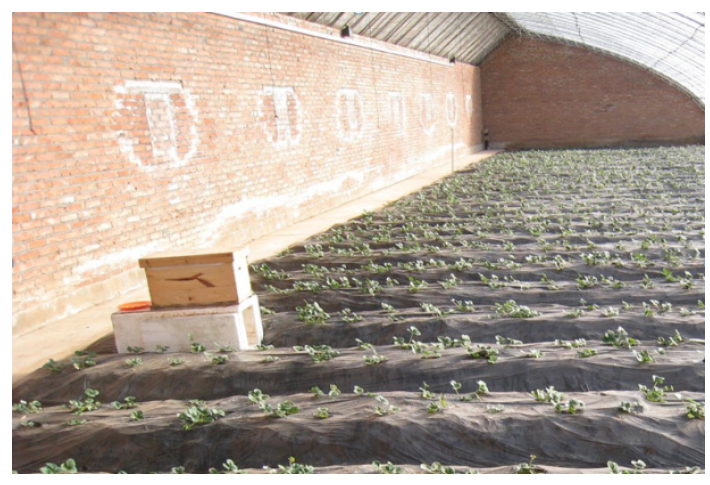

c)

Figure 3. Chinese solar greenhouse

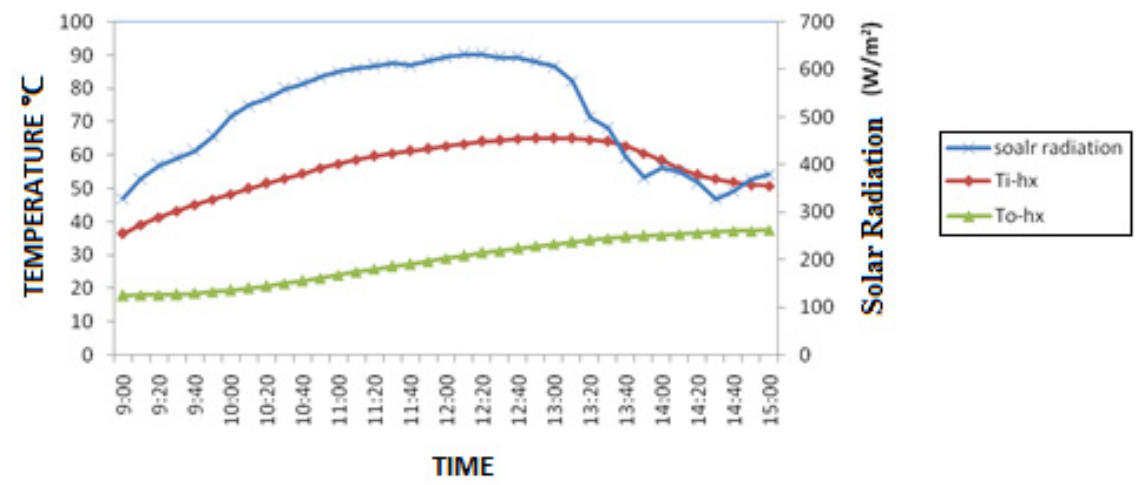

Figure 4A. Air temperature variation for different air flow rate, $0.2 \mathrm{~kg} / \mathrm{min}$

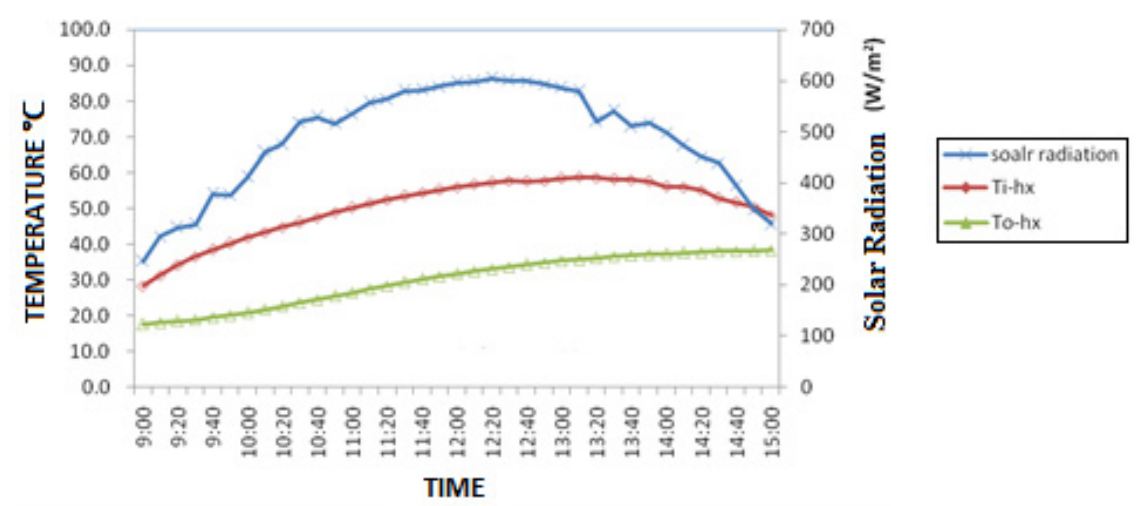

Figure 4B. Air temperature variation for different air flow rate, $0.6 \mathrm{~kg} / \mathrm{min}$ 


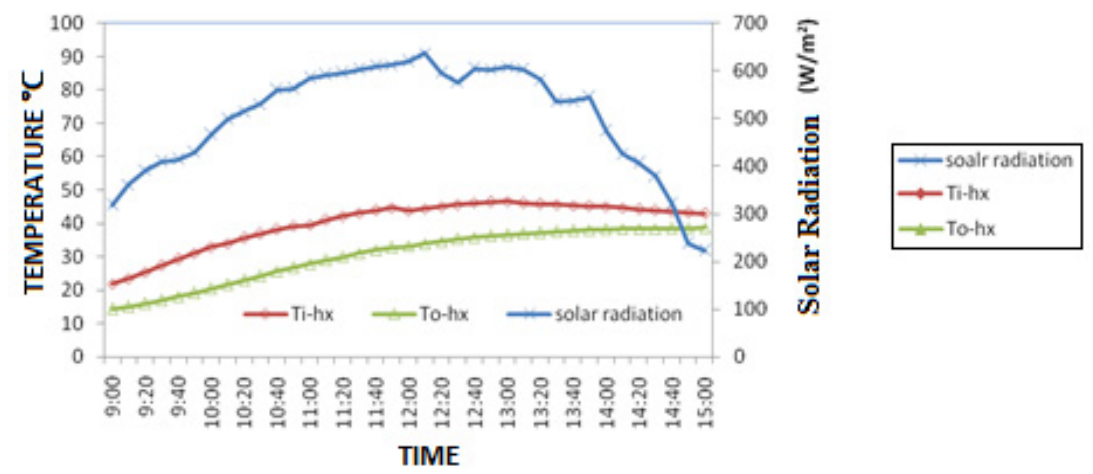

Figure 4C. Air temperature variation for different air flow rate, $1.0 \mathrm{~kg} / \mathrm{min}$

\section{Energy Analysis}

\subsection{PCM Analysis}

The collector unit and the PCM were tested to study its thermal performance and efficiency. The data collected was used to draw the efficiency curve of the heat exchanger and the collector unit at different mass flow rates.

Energy efficiency during the charging period is defined as the ratio of heat stored in the PCM to the total solar energy received.

$$
n=\frac{\text { stored heat in } P C M}{\text { Solar energyinput }}
$$

The total energy efficiency obtained from the absorption plate during charging period $n(t)$ can be described by following equation:

$$
n(t)=\frac{Q_{S}(t)}{Q_{t}(t)}(100)
$$

A heat exchanger is a piece of equipment built to make an efficient heat transfer from one medium to another, as heat is transferred by convection form, there are PCM bars with air circulating inside the surroundings of the serpentine chamber. The heat supplied by the heat storage unit during the discharging period can be calculated by the following equation:

$$
Q_{r}(t)=V \rho c_{p}\left[T_{o}(t)-T_{i}(t)\right]
$$

The system COP during a discharging period can be described as the heat supplied by the heat exchanger to the energy consumption of the fan.

\section{Results and Discussion}

$$
\mathrm{COP}=\frac{\mathrm{Q}_{\mathrm{r}}(\mathrm{t})}{\mathrm{Q}_{\mathrm{d}}}
$$

Few studies have been carried out on the application of solar concentrators and PCM heat exchangers for greenhouse air heating systems, as the literature review demonstrates, there is not much information available, especially for application in cold regions. A low mass air flow can get a lower outlet air temperature and a bigger temperature difference between inlet and out let. As was demonstrated when the air flow rate was increased from $2.0 \mathrm{~kg} / \mathrm{min}$ to $0.6 \mathrm{~kg} / \mathrm{min}$, the heat collection of the PCM heat exchanger was less, and a much better performance was achieved when it was reduced from $1 \mathrm{~kg} / \mathrm{min}$ to $0.2 \mathrm{~kg} / \mathrm{min}$. Figure 5 shows the hourly amount of heat collected in accumulator for different air flow rates. Due to the efficient exchange in the PCM heat exchanger chamber, the temperature recorded at the outlet was always lower during the heat collection cycle than at the inlet, what means that the PCM could easily collect the heat from the air. Also, it was founded that the average highest net efficiency happens with a mass flow rate of $0.6 \mathrm{~kg} / \mathrm{min}$. Figure 6 shows the net efficiency of PCM heat exchanger during test time at different mass flow rates.

Latent Heat Storage (LHS) has the advantage to store the heat energy collected during the day; this energy is released during night when heat energy is required to maintain an optimum indoor temperature. But in order to complete this process, first, it is necessary to convert the solar radiation into heat energy; such task can be 
accomplished by using a solar collector unit. In this work the solar collector unit was designed to be held over the north wall inside the Chinese solar greenhouse, during the day it helps covering a percentage of the heating requirement, and supplies the heat energy that needs to be stored into the LHS unit, being its main function during night time when the heating on demand was high. It was founded that the performance of this solar collector is greatly reduced during cloudy days, when is required to make use of alternative heating sources. The absorption plate design present a good performance but a better design could help to improve the overall efficiency of the system. The LHT unit and insulation system provides heat for about 4 hours. Although, it is recommended to be used in combination with conventional heating sources in order to achieve an appropriate temperature. Table 1 show the variations of indoor temperature of the green house and the temperature of PCM.

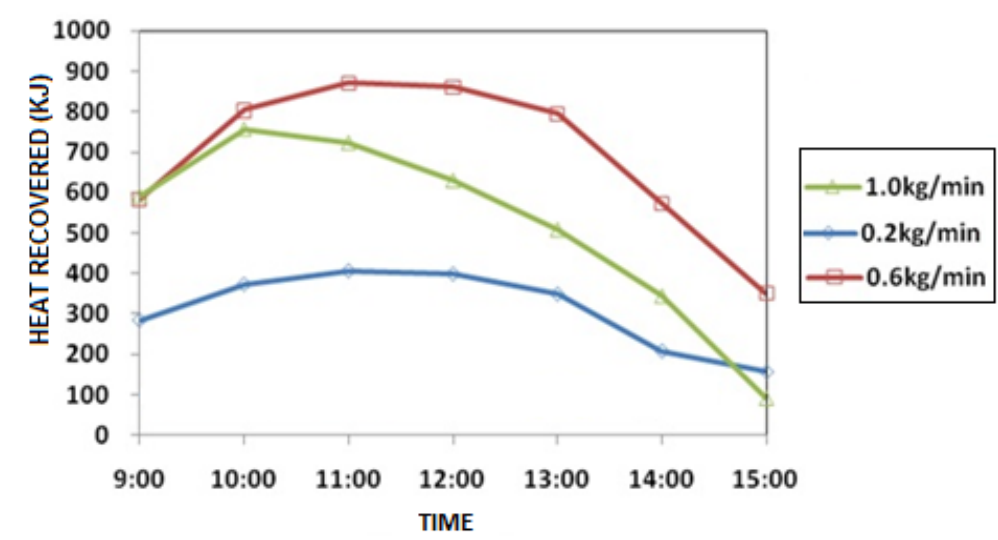

Fig 5, Variations of hourly heat storage in heat exchanger for different Air flow rate

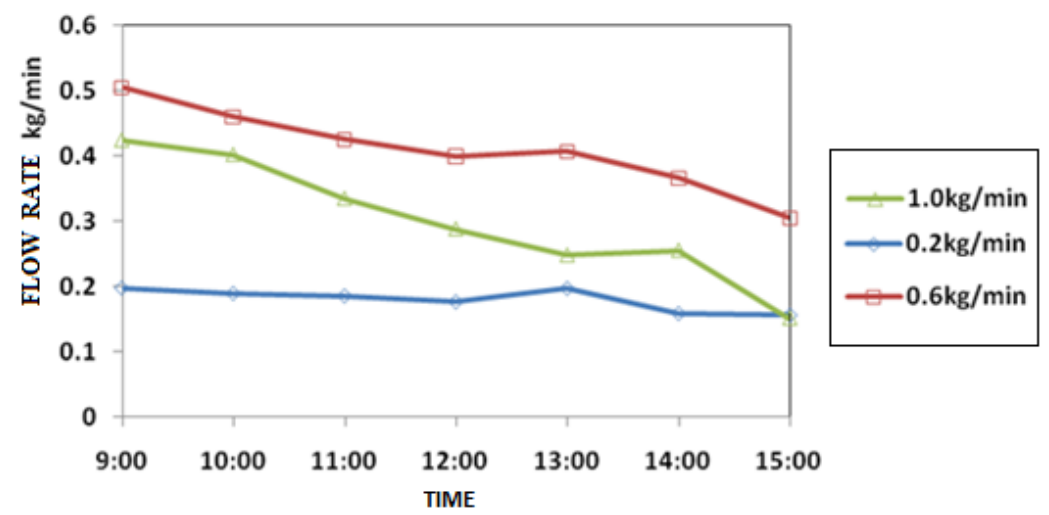

Figure 6. Variations of hourly heat efficiency for different air flow rate

Table 1. Amount of heat recovered

\begin{tabular}{lllc}
\hline Mass flow tare & $\begin{array}{l}\text { Recovered heat from the accumulator } \\
\text { during the discharging period(KJ) }\end{array}$ & Total power consumption $(\mathrm{KJ} / 24 \mathrm{~h})$ & $\mathrm{COP}$ \\
\hline $0.2 \mathrm{~kg} / \mathrm{Min}$ & 1340.0 & 432.0 & 3.1 \\
$0.6 \mathrm{~kg} / \mathrm{Min}$ & 2272.0 & 1296.0 & 1.8 \\
$1.0 \mathrm{~kg} / \mathrm{Min}$ & 2070.0 & 2074.0 & 1.0 \\
\hline
\end{tabular}

The amount of heat contribution and heat recover by the PCM heat exchanger of this system was calculated by using the Equation (2). 


\section{Conclusion}

Experiments were carried out to investigate the performance of an integrated PCM solar wall model unit during the charging and discharging processes, this system represents an alternative solution to farmers in remote areas. The following conclusion may be drawn within the parameters investigated in the present study:

- $\mathrm{CH}_{3} \mathrm{COONa} \cdot 3 \mathrm{H}_{2} \mathrm{O}-\mathrm{HCONH}$, an organic/inorganic eutectic mixture, is suitable for latent heat storage, which is another choice besides the well know calcium chloride hexahydrated and paraffin wax.

- The results of the present experimental work agree well with the one reported by Abdel-Monem and El-Bassuoni et al., who found that the pseudo-binary system with a ratio of 3:1 forms a eutectic mixture at $40.5^{\circ} \mathrm{C}$ accompanied by large heat of fusion.

- Air flow rate is a key factor in the operating process. During the charging process, the system stored a maximum solar gain and most efficiently optimum value $(0.6 \mathrm{~kg} / \mathrm{Min})$. In the discharging process, the duration of the Output Power depends on this parameter.

- The solar collector was capable to supply 4 hours of heat energy for the greenhouse. However, it is strongly recommended to combine this system with a conventional heating system to fulfill the heating demand during winter season in the northern region of China.

- The thermal performance of this system is greatly affected by cloudy days, and is more efficient in days with high solar radiation and high air temperatures.

- Material and design involved in the construction of solar collector plays an important role in its performance. It is suggested to separate the absorption plate from the bottom to let the air circulate over both faces of the collector, resulting in a better performance and air heat collection.

- Future studies should focus on: interaction between the large areas of built-in solar wall and greenhouse environment. This could help to increase the thermal performance of this unit.

\section{Acknowledgements}

The authors gratefully acknowledge the financial support from the Center for Protected Agriculture and environmental Engineering (CAAS). Also, special thanks to all the working staff in the green house array who collaborated in the construction of the system in the suburbs of the city of Beijing, China.

\section{References}

Beijing. (2008). The Columbia Encyclopedia (6th ed.).

Benli, H., \& Durmus, A. (2009). Performance analysis of a latent heat storage system with phase change material for new designed solar collectors in greenhouse heating. Solar Energy, 83, 2109-2119.

Boulard, T., Razafinjohany, E., Baille, A., Jaffrin, A., \& Fabre, B. (2003). Performance of greenhouse heating system with a phase change material. Agricultural and Forest Meteorology, 52, 303-318. http://dx.doi.org/10.1016/0168-1923(90)90088-N

Christian, V. Z. (2011). Integrated greenhouse system for mild climates. Springer.

El-Bassuani, A. M. A., Tayeb, A. M., Helwa, N. H., \& Fathy, A. M. (2003). Modification of urea-sodium acetate trihydrate mixture for solar energy storage. Renew Energy, 28, 1629-1643. http://dx.doi.org/10.1016/S0960-1481(02)00052-6

Eman-Bellah, S., Mettaweea, \& Ghazy, M. R. (2006). Assassab Experimental study of a compact PCM solar collector. Energy, 31, 2958-2968. http://dx.doi.org/10.1016/j.energy.2005.11.019

Ghoneim, A. A., Klein, S. A., \& Duffie, J. A. (1991). Analysis of collector-storage building walls using phase-change materials. Solar energy, 47(3), 237-242. http://dx.doi.org/10.1016/0038-092X(91)90084-A

Hamid, E. Q. (2009). Numerical analysis of a coupled solar collector latent heat storage unit using various phase change materials for heating the water. Energy Conversion and Management, 50, 247-254. http://dx.doi.org/10.1016/j.enconman..2008.09.038

Huseyin, B., \& Aydin, D. (2008). Evaluation of ground-source heat pump combiened latent heat storage system performance in greenhouse heating. Energy and Buildings, 41(2), 220-228. http://dx.doi.org/10.1016/j.enbulding.2008.09.004 
Huseyin, B., \& Aydin, D. (2009). Performance analysis of latent heat storage system with phase change material for new designed solar collector in greenhouse heating. Solar Energy, 83(12), 2109-2119. http://dx.doi.org/10.1016/j.solener.2009.07.05

Kern, M., \& Aldrich, R. A. (1979). Phase change energy storage in a greenhouse solar heating system. Paper presented summer Meeting of ASAE and CSAE. University of Manitoba, Winnipeng, Canada.

Koca, A., Oztop, H. F., Koyun, T. K., \& Varol, Y. (2008). Energy and exergy analysis of a latent heat storage system with phase change material for a solar collector. Renewable Energy, 33, 567-574. http://dx.doi.org/10.1016/j.renene.2007.03.012

Laurent, Z., Annabelle, J., Stephane, L., Yvan, D., \& Daniel, R. (2012). Experimentakl study of small wall integrating phase change material. Solar Energy, 86(1), 208-219 http://dx.doi.org/10.1016/j.solener.2011.09.026

Levav, N., \& Zamir, N. (n.d.) Phase change material for heat storage in greenhouse in: REUR technical series L: greenhouse heating with solar energy. CNRE, pp. 163-166.

Li, J. H., Zhang, G., \& Wang, J. Y. (1991). Investigation of eutectic mixture of sodium acetate trihydrate and urea as latent heat storage. Solar Energy, 47(6), 443-445. http://dx.doi.org/10.1016/0038-092X(91)90112-A

Mahmud, M. A., Sopian, K., Alghoul, M. A., Sohif, M., \& Ruslan, M. H. (2011). Review of solar air collectors with thermal storage units. Renewable and Sustainable Energy Reviews, 15, 1476-1490. http://dx.doi.org/10.1016/j.rser.2010.10.019

Öztürk, H. H., \& Başçetinçelik, A. (2003). Energy and Exergy Efficiency of a Packed-bed Heat Storage Unit for Greenhouse Heating. Biosystems $\quad$ Engineering, $231-245$. http://dx.doi.org/10.1016/S1537-5110(03)00134-X

Sethi, V. P., \& Sharma, S. K. (2008). Survey and evaluation of heating technologies for worldwide agricultural greenhouse applications. Solar Energy, 82, 832-859. http://dx.doi.org/10.1016/j.solener.2008.02.010

Wada, T., Kimura, F., \& Yamamoto, R. (1983). Studies on salt hydrate for latent heat storage. III. pseado-binary system, CH3CO2Na`3H2O-HCONH2. The Chemical Society of Japan, 56, 1575-1576.

Zalba, B., Jose, M. M., Luisa, F. C., \& Harald, M. (2003). Review on thermal energy storage with phase change: materials, heat transfer analysis and applications. Appl Therm Eng, 23, 251-283. http://dx.doi.org/10.1016/S1359-4311(02)00192-8

Zalewski, L., Joulina, A., Lassuea, S., Dutilc, Y., \& Roussec, D. (2011). Experimental study of small-scale solar wall integrating phase change material. Solar Energy, 86(1), 208-219. http://dx.doi.org/10.1016/j.solener.2011.09.026 